\title{
First report of powdery mildew of Capsella bursa-pastoris caused by Golovinomyces orontii in Slovenia
}

\author{
Sebastjan Radisek ${ }^{1} \cdot$ Jernej Jakse ${ }^{2} \cdot$ Ting-ting Zhao $^{3} \cdot$ Sung-Eun $\mathrm{Cho}^{3} \cdot$ Hyeon-Dong Shin ${ }^{3}$
}

Received: 19 February 2018 / Accepted: 6 May 2018 / Published online: 22 May 2018

(C) Società Italiana di Patologia Vegetale (S.I.Pa.V.) 2018

During the summer and autumn of 2017, several dozen plants of Capsella bursa-pastoris (L.) Medik. growing wild in a public park in Ljubljana $\left(46^{\circ} 03^{\prime} 32^{\prime \prime} \mathrm{N} 14^{\circ} 29^{\prime} 51^{\prime \prime}\right.$ E), Slovenia, were found infected with a powdery mildew. Conidiophores arising from the lateral part of hyphae were erect, $100-240 \times 10-12 \mu \mathrm{m}$, and producing conidia in chains with sinuate outline. Conidia were hyaline, ellipsoid to cylindric-oval, $30-46 \times 14-20 \mu \mathrm{m}$, and devoid of distinct fibrosin bodies. Germ tubes were produced at the perihilar position of conidia. Chasmothecia were not observed during our survey. To confirm the identity, genomic DNA was extracted from representative isolate IHPS-F50 and ITS region of rDNA was amplified using the primers ITS1F and ITS4 and sequenced (GenBank accession no. MG952279). A GenBank BLAST search revealed 99\% similarity to Golovinomyces orontii ex Capsella bursapastoris from Switzerland (AB769458). Based on morphological characteristics and molecular analysis, the fungus was identified as G. orontii (group 2) (Castagne) V.P. Heluta (Braun and Cook 2012; Takamatsu et al. 2013). Capsella bursa-pastoris has been recorded as host plant of G. orontii in Germany, Poland, and Switzerland, but not in Slovenia. Formerly, Erysiphe cruciferarum was recorded on C. bursa-pastoris in Yugoslavia (Amano 1986). To our knowledge, this is the first report of powdery mildew caused by G. orontii on C. bursa-pastoris in Slovenia. Golovinomyces orontii is regarded as species complex with very wide host range (Braun and Cook 2012). Therefore, information on the Capsella powdery mildew would be helpful for understanding this species complex. Voucher specimens are available in the phytopathological herbarium of the Slovenian Institute of Hop Research and Brewing (IHPS-F50), and in the Korea University herbarium (KUS-F29981).

\section{References}

Amano K (1986) Host range and geographical distribution of the powdery mildew fungi. Japan Sci. Soc. Press, Tokyo, Japan

Braun U, Cook RTA (2012) Taxonomic Manual of the Erysiphales (Powdery Mildews), CBS Biodiversity Series No. 11. CBS, Utrecht, The Netherlands

Takamatsu S et al (2013) Mycologia 105:1135
Sebastjan Radisek

sebastjan.radisek@ihps.si

1 Slovenian Institute of Hop Research and Brewing, Cesta Zalskega Tabora 2, SI-3310 Zalec, Slovenia

2 Biotechnical Faculty, Agronomy Department, University of Ljubljana, Jamnikarjeva, 101, SI-1000 Ljubljana, Slovenia

3 Division of Environmental Science and Ecological Engineering, Korea University, Seoul 02841, South Korea 